\title{
INTELIGÊNCIA ARTIFICIAL E AS CONFIGURAÇÕES CONTEMPORÂNEAS DO DIREITO: DA INOVAÇÃO TECNOCIENTÍFICA À INOVAÇÃO JUSTECNOLÓGICA
}

\author{
ARTIFICIAL INTELLIGENCE AND THE CONTEMPORARY CONFIGURATIONS OF LAW: \\ FROM TECHNOLOGICAL INNOVATION TO IUSTECHNOLOGICAL INNOVATION
}

\section{Wilson Engelmann}

Pós-Doutor em Direito Público-Direitos Humanos pelo Centro de Estudios de Seguridad (CESEG), da Facultad de Derecho da Universidade de Santiago de Compostela, na Espanha; Coordenador Executivo do Mestrado Profissional em Direito da Empresa e dos Negócios da Universidade do Vale do Rio dos Sinos - UNISINOS, São Leopoldo, Rio Grande do Sul, Brasil; Professor e Pesquisador do Programa de Pós-Graduação em Direito - Mestrado e Doutorado da UNISINOS; Bolsista de Produtividade em Pesquisa do CNPq. E-mail: WEngelmann@unisinos.br

\section{Clarice Gonçalves Pires Marques}

Doutoranda em Direito Público do Programa de Pós-Graduação em Direito da Universidade do Vale do Rio dos Sinos - UNISINOS - Bolsista CAPES/PROEX.

E-mail: claricepiresmarques@gmail.com

Recebido em: 20/08/2020

Aprovado em: 22/04/2021

\begin{abstract}
RESUMO: O presente estudo pretende identificar se o "diálogo entre as fontes" do Direito pode ser adotado a fim de contemplar novos direitos que emergem da interação entre humanos/as e a Inteligência Artificial. Analisou-se o desenvolvimento e uso da I.A. no campo da ficção utilizando como recorte a obra A. I. (Artificial Intelligence), divulgada em 2001, bem como na contemporaneidade buscando as aplicações mais recentes. Identificou-se a carência de regulação tanto em nível nacional quanto no direito comparado, bem como a existência de orientações do Parlamento Europeu e iniciativas de organizações transnacionais em parcerias como a Partnership on A. I., voltadas para o desenvolvimento de efetiva normatização. Notou-se que para contemplar os novos direitos que emergem da interação entre humanos/as e I. A. é possível e necessária a utilização do "diálogo entre as fontes" operando uma releitura do sistema jurídico verticalizado/hierarquizado por uma interação horizontalizada e flexível, proporcionando o avanço "justecnológico" que atenda à velocidade do progresso da tecnologia em questão. O método empreendido foi o fenomenológico-hermenêutico, baseado na filosofia de Martin Heiddeger e Hans-Georg Gadamer, e se vale da técnica de pesquisa bibliográfica e documental.
\end{abstract}

Palavras-chave: Direito. Inteligência Artificial. Diálogo entre as Fontes do Direito.

ABSTRACT: The present study aims to identify if the "dialogue between the sources of law" can be adopted in order to contemplate new rights that emerge from the interaction between humans and artificial intelligence (AI). The development and use of AI in the field of fiction was analyzed, 
using AI (artificial intelligence), published in 2001, as well as contemporary searching for the latest applications, as well as the lack of regulation at both national and comparative law, as well as the existence of European Parliament Guidelines and initiatives of transnational organizations in association such as Partnership on AI, focused on the development of effective standardization, it has been noted that in order to contemplate the new rights that emerge from human/AI interaction, it is possible and necessary to use "dialogue between law" operating a rereading of the verticalized/hierarchical legal system by interfaces will horizontalized and flexible, providing breakthrough "Iustechnological" that meets the speed of progress of technology in question. The method adopted was the phenomenological-hermeneutic, based on the philosophy of Martin Heiddeger and Hans-Georg Gadamer, and uses the technique of bibliographic and documentary research.

Keywords: Law. Artificial intelligence. Dialogue between the Sources of Law.

SUMÁRIO: Introdução. 1 A atualidade da inteligência artificial e seus dilemas. 2 As (des)configurações do direito: Do brasil ao âmbito internacional. 3 Diagnóstico e prognóstico em termos de regulação. $4 \mathrm{O}$ diálogo de fontes como alternativa às fagilidades do direito em face da ia. Considerações finais. Referências.

\section{INTRODUÇÃO}

A trajetória da humanidade é marcada por uma série de invenções que a impulsionou em um processo evolutivo, em termos tecnológicos, modificando concepções de tempo, espaço e de si. Com isso, avanço e destruição sempre caminharam lado a lado, fogo, ferramentas, vidro, pólvora, bússola, lentes, motor a vapor e elétrico, eletricidade, medicamentos, fissão nuclear, internet, engenharia genética. São exemplos ínfimos diante das inúmeras criações que resultaram em três Revoluções Industriais, chegando agora na chamada Quarta Revolução Industrial. Nesta quadra da história, o surgimento de inovações tecnológicas ocorre em ritmo acelerado ${ }^{1}$, suscitando inúmeras discussões não só no que se refere ao ponto de vista prático de sua criação, mas com relação aos dilemas que impõe cada avanço. ${ }^{2} \mathrm{O}$ tema deste estudo é a Inteligência Artificial e se buscará mencionar algumas das suas mais recentes utilizações. Considerando as questões que podem emergir destas análises, a problemática que se estabelece é: Considerando o estágio atual das inovações tecnocientíficas, sob quais fundamentos o diálogo entre fontes do Direito pode ser adotado a fim de contemplar novos direitos que emergem da interação entre humanos/as e a Inteligência Artificial?

O objetivo geral que se estabeleceu foi identificar se o diálogo entre fontes do Direito pode ser adotado a fim de contemplar novos direitos que emergem da interação entre humanos/as

\footnotetext{
1 Um levantamento realizado pelo Massachusetts Institute of Technology (MIT) em 2018 apontou para dez inovações tecnológicas que, de acordo com suas análises, afetariam profundamente a vida das pessoas naquele ano. Dentre tais inovações estavam elencadas a impressão 3D de metais, embriões artificiais, cidades sensíveis, inteligência artificial, redes neurais em duelo, fones de tradução simultânea, gás natural sem carbono, ferramenta de privacidade online, adivinhação genética e computação quântica (REVISTA ÉPOCA, 2018). Em 2019, o mesmo Instituto aponta para inovações como vacinas personalizadas contra o câncer, hambúrgueres vegetais com sabor a carne, relógios com eletrocardiogramas, destreza robótica, energia produzida por fusão e fissão nuclear, testes sanguíneos de diagnóstico de bebês prematuros, cápsulas ingeríveis que captam imagens do intestino, máquinas que "capturam" dióxido de carbono, sanitas que tratam os dejetos in situ. e programas de inteligência artificial de conversação (IHU ON-LINE, 2019).

${ }^{2}$ Todas estas invenções/produções podem refletir nos âmbitos social, psicológico, ambiental e, por consequência, também no âmbito jurídico, pois de sua criação e seus usos decorrem direitos e obrigações, bem como a necessidade de regulamentação. Ainda, muitas vezes são desconhecidos ou pouco conhecidos os riscos da disponibilização dos produtos para a população.
} 
e a Inteligência Artificial, considerando do estágio atual das inovações tecnocientíficas. Como objetivos específicos se pretende observar algumas aplicações da Inteligência Artificial na ficção e na contemporaneidade; delimitar a atual configuração do Direito e sua aplicação em possíveis questões que envolvam a proteção e regulação de direitos frente ao uso da Inteligência Artificial; investigar pontos fortes e frágeis da legislação frente ao uso da Inteligência Artificial; analisar a viabilidade da utilização do diálogo das Fontes do Direito para compor a produção de inovação justecnológica a fim de atender as controvérsias decorrentes da produção/utilização da Inteligência Artificial.

A hipótese sopesada foi a de que tendo em vista a multiplicidade de fragmentos normativos existentes sobre novas tecnologias, a constitucionalização do Direito Privado - a partir das proposições teóricas de Wilson Engelmann, Gunther Teubner e Mireille Delmas Marty - é possível adotar formas de diálogo entre Fontes do Direito, substituindo estruturas hierárquicas por outras mais flexíveis e adaptadas à velocidade exigida pelas questões suscitadas. $\mathrm{O}$ método empregado para atender tal propósito foi o fenomenológico-hermenêutico, fundado no pressuposto de que os pesquisadores estão inseridos no mundo onde as pesquisas sobre Direito e Novas Tecnologias são desenvolvidas, sendo atingidos pelos seus resultados. ${ }^{3}$ Foi utilizada a técnica de pesquisa bibliográfica e documental em pesquisa qualitativa. O estudo se justifica na medida em que pode servir de subsídio para novas discussões acerca do tema, com a finalidade de encontrar possibilidades para o déficit regulatório existente no campo delimitado.

\section{A ATUALIDADE DA INTELIGÊNCIA ARTIFICIAL E SEUS DILEMAS}

Há um arcabouço considerável de obras literárias e cinematográficas que envolvem a interação entre humanos/as e Inteligência Artificial. A arte é um importante elemento cultural vez que retrata os anseios e percepções de uma sociedade, tanto quanto projeta suas angústias e seu imaginário. Na ficção são retratadas Inteligências Artificiais dotadas de corpos com variadas formas, algumas com aparência humana de difícil distinção. São robôs dotados de Inteligência para realizar as mais variadas tarefas, trabalhar nas mais diversas profissões e funções como domésticas, na indústria, ciências, babás, ou seja, para fazer tudo que as pessoas não desejam ou não podem fazer, constituem universos imaginários em que androides e humanos/as se inter-relacionam e se confundem formando a multidão.

Na obra Inteligência Artificial, dirigida por Steven Spielberg (INTELIGÊNCIA ARTIFICIAL, 2001) o protagonista é um androide em forma de criança, denominado David, cuja inteligência é construída a partir de neurônios e o qual possui subconsciente. Assim, ele desenvolve capacidades humanas como amar, sonhar, se autodeterminar e refletir sobre sua existência. No filme é colocado o seguinte dilema ético: se o androide pode amar, qual é a responsabilidade de quem o adquire? A questão é, o que diferenciará Inteligências Artificiais da Inteligência Emocional de humanos/as, se ao aprimorá-los puderem desenvolver estas capacidades? Quais as implicações para quem cria e quem adquire, e para quê? Seriam elas sujeitos de Direito? Que Direitos e obrigações humanos/as teriam com relação a elas? No campo da ficção não há limites. Será a ficção o prenúncio do futuro? São muitas as perguntas que surgem ao se debruçar sobre estas reflexões. Mas e a realidade? Em que patamar de desenvolvimento se encontra esta tecnologia?

Ainda que diferentes da ficção, as Inteligências Artificiais contemporâneas têm impactado na vida das pessoas e evoluído desde que começaram a ser produzidas. O termo "Inteligência

\footnotetext{
3 Nesse sentido, não se trata de uma investigação alheia aos pesquisadores, pois estão inseridos no mundo em que a pesquisa será desenvolvida. Aí o significado do fenômeno. Já essa constatação fenomênica receberá a atribuição de sentido, a partir do círculo hermenêutico, especialmente por meio das contribuições de Martin Heidegger e Hans-Georg Gadamer. (ENGELMANN, 2010).
} 
Artificial"4, o qual daqui em diante será referido como IA, surge a partir dos anos 50 do século $\mathrm{XX}^{5}$, quando Alan Turing questiona se uma máquina poderia pensar e, posteriormente se poderia realizar comportamentos humanos inteligentes de forma tão perfeita que humanos/as se confundiriam ao tentar distinguir se determinadas tarefas teriam sido realizadas por eles/as ou por máquinas (TEIXEIRA; QUILICI GONZALES, 1983). Dotada de capacidade para analisar dados e oferecer soluções a partir de uma programação previamente estabelecida a IA vem sendo utilizada para atendimento de clientes no comércio e sistema bancário, para transporte, para análise de dados na área de saúde, na gestão de recursos humanos (para recrutamento e seleção, na gestão de materiais e até mesmo no sistema judiciário. ${ }^{6}$

A exemplo disso cita-se a IA criada pela Amazon para realizar a análise de currículos. A tecnologia passou a ser utilizada a partir de 2014 e seu uso foi descartado em 2015 (REUTERS, 2018; UOL, 2018) . A empresa identificou que o sistema não recrutava desenvolvedores de software e outros cargos técnicos de maneira isenta com relação ao gênero, o que se deve ao fato de que a IA em questão foi treinada para operar a seleção analisando padrões em currículos entregues pelo período de 10 anos na empresa. Tendo em vista que a maioria era de currículos de candidatos do sexo masculino o sistema ensinou para si que candidatos do sexo masculino eram preferíveis. Mesmo após a alteração dos programas a máquina criou outras formas de discriminação na hora de selecionar candidatos/as, ou seja, criou sua própria experiência.

Refere-se ainda outras IA que coexistem com boa parte da população como as desenvolvidas e utilizadas nos smartphones, programadas para reconhecer a voz humana e realizar buscas, abrir e fechar aplicativos, dentre outras utilizações. Convive-se com I. A. que, a partir de escolhas de seleção de filmes, músicas, produtos, montam menus automaticamente de seleção destes itens, como plataformas do Facebook, Netflix, Spotfy. Aplicações bem comuns envolvem a tarefa de separar e-mails comuns de spam, identificar e isolar vírus malware, sites de pesquisa como Google, reconhecimento facial, itens interligados com a internet das coisas como automóveis inteligentes, casas inteligentes e até mesmo em fábricas como o caso da Siemens, na Alemanha (TD, 2017). Sophia é um robô criado pela Hanson Robotics, de Hong Kong. Seu desenvolvedor David Hanson lhe deu feições humanas femininas e capacidade de linguagem inspiradas na atriz Audrey Hepburn, o robô possui cidadania concedida pela Arábia Saudita, e faz turnês mundiais com seu criador a fim de divulgar o trabalho da empresa (GALILEU, 2018).

Em 26 de setembro de 2019, a Agência de Notícias BBC News em notícia reproduzida no Brasil através do portal de notícias G1, relata espanto com a manchete "Assustadora criança-robô que sangra, grita e simula dor". Trata-se de um simulador de pacientes pediátricos desenvolvido

\footnotetext{
${ }^{4}$ Inteligência artificial (IA) é um ramo da ciência da computação que usando algoritmos definidos por especialistas é capaz de reconhecer um problema, ou uma tarefa a ser realizada, analisar dados e tomar decisões, simulando a capacidade humana. Sistemas computadorizados de apoio à decisão já existem há décadas, mas o aumento da velocidade de processamento e de armazenamento de informação dos computadores, permitiu analisar um grande volume de dados em nanosegundos propondo soluções de problemas, orientando a proposta e tomada de decisões, realizando tarefas sem receber instruções diretas de humanos. (LOBO, 2018, p.1).

5 O fascínio dos/as humanos/as por construir e utilizar máquinas à sua imagem e semelhança data de período bem anterior ao séc. XX. No séc. XVIII foi construída uma máquina para jogar xadrez denominada "O Turco". A máquina foi elaborada por um inventor Húngaro chamado Wolfgang Von Kempelen, para ser utilizada pela Imperatriz da Áustria, Maria Teresa. A máquina existiu de 1770 a 1854 quando foi destruída por um incêndio. Acreditava-se que seria um autômato com inteligência artificial capaz de vencer competidores fortes, no entanto, em 1820 foi revelado que no balcão acoplado abaixo do robô - um manequim em tamanho real - havia espaço para que um humano o operasse e, portanto, não se tratava de uma máquina autônoma, dotada de inteligência capaz de tomada de decisões, mas sim uma máquina operada por um jogador experiente, ou seja, um simulacro. (SARMATZ; FONTENELLE, 2002).

6 Embora não se possa falar em androides integrados na multidão, convive-se com o fato de que a Inteligência Artificial "reconhece imagens, permite interações computadorizadas em linguagem aberta, escrita e falada, percebe relações e nexos, entende conceitos e não apenas processa dados, segue algoritmos e cria sua própria experiência ('machine learning')." (LOBO, 2018, p. 1).
}

Revista de Direito Brasileira | Florianópolis, SC | v. 28 | n. 11 | p.405-421 | Jan./Abr. 2021 
nos Estados Unidos pela empresa Gaumard Cientific. Chamada de Pediatric Hal é uma máquina com feições de menino, branco, ruivo, de olhos azuis, aparentando ter entre 6 a 8 anos, tem pulsação e medo de agulhas, grita e chama pela mãe no leito do hospital, sangra e pode ter paradas cardíacas. Sua finalidade é simular situações para a aprendizagem de estudantes de medicina e a criação tem sido considerada assustadora, tendo em vista o grau de realismo que apresenta. A tecnologia está sendo usada pelo hospital infantil Lucile Packard, da Universidade de Stanford (G1, 2018).

As IA também estão se inserindo na esfera jurídica. O Ministério da justiça da Estônia está desenvolvendo o primeiro "Juiz Robô", o projeto está em fase inicial e a pretensão é a de que seja capaz de julgar casos de menor complexidade e valores até US\$ 8 (oito mil dólares), a tomada de decisão se estabelecerá a partir de banco de dados com todas as leis do país (SILVA, 2019). Com isso, o governo da Estônia não visa, ao menos inicialmente, substituir totalmente juízes/as humanos/as, pois as decisões podem ser revistas em grau de recurso, porém a ideia é reduzir o trabalho burocrático e oportunizar a concentração em casos mais complexos.

No Brasil conta-se com Victor, em utilização desde 30 de agosto de 2018, no Supremo Tribunal Federal. De acordo com declaração da Ministra Carmen Lúcia, no portal de notícias do STF, a tecnologia é utilizada para a conversão de imagens em textos no processo digital, separação do começo e do fỉm de um documento no acervo do Tribunal, separação e classificação das peças processuais mais utilizadas nas atividades do STF e identificação dos temas de repercussão geral de maior incidência (STF, 2018). Ainda não se sabe que outras habilidades serão desempenhadas por Victor no futuro e será capaz de julgar ações como pretende o governo da Estônia com seu "robô juiz". No entanto, a tendência é a de que se diversifique e popularize a utilização de IA no judiciário.

Se esta tecnologia está revolucionando a vida humana agilizando e, realizando tarefas, servindo como cobaia, analisando dados, tomando decisões, julgando processos e mais um sem número de possibilidades, como todo avanço tecnológico, também oferece riscos e já se tem notícias de situações bem sombrias com relação à utilização da mesma. Na Alemanha, em 2015, um funcionário foi morto por um robô na fábrica da Wolkswagen, enquanto instalava o equipamento. Devido a um erro desconhecido a máquina esmagou o peito do trabalhador, o qual não resistiu aos ferimentos (G1, 2015).

Em 2016 um robô com IA, fabricado pela empresa Knightscope, sediada no Vale do Silício, utilizado na segurança de um shopping em Palo Alto, na Califórnia, nos Estados Unidos da América, avançou em direção a uma criança de um ano e quatro meses, batendo em sua cabeça e posteriormente passando por cima de seu pé. Embora o robô tivesse peso equivalente a 136 quilos e um metro e meio de altura a criança sofreu apenas pequenas escoriações, mas o incidente foi suficiente para se questionar a segurança de seu uso (COELHO, 2016). No mesmo ano, em novembro, durante uma feira de tecnologia chamada China Hi-Tech, realizada na província de Shenzhen, um outro modelo denominado Xiao Pang, produzido pela empresa EFrobots Evolver, vendido como acompanhante para crianças (vendido, na época, pelo valor de US\$1.460 - mil e quatrocentos dólares), avançou violentamente em direção a uma visitante, causando-lhe hematomas e escoriações (PORTAL DE NOTÍCIAS VOIT, 2016).

Estes são alguns exemplos do quão complexa é a atualidade com relação à IA, existem incontáveis outras aplicações que não foram mencionadas. Seria difícil compilar todos os usos e efeitos desta tecnologia na escrita que foi aqui proposta, mas o que se pode refletir é que a mesma produz impactos significativos. No que tange ao Direito, a grande demanda é o déficit de regulação acerca da IA, conforme se observa a seguir. 


\section{AS (DES)CONFIGURAÇÕES DO DIREITO: DO BRASIL AO ÂMBITO INTERNACIONAL}

Quando se traz a questão da produção e uso da I. A. para o plano concreto se identifica o abismo legislativo do qual se está diante. Nota-se em primeira análise que se conta com a Lei 9.279/1996 (Lei de Propriedade Industrial), Lei 9.610/1998 (Lei de Direitos Autorais), Lei 9.609/1998 (Lei de Programa de Computador), Decreto 2.556/98 (Proteção e Comercialização de Programa de Computador) e Lei 13.709/2018 (Lei de Proteção de Dados Pessoais). Resumidamente a Lei 9.279/1996, no art. 10, refere o termo "programas de computador em si" apenas para dizer que não se aplica para fins de registro, pois estes não se enquadram como invenção e nem modelo de utilidade. Já a Lei 9.610/98 estabelece o direito de propriedade autoral sobre programas de computador em seu art. $7^{\circ}$, e remete à lei específica (que é a Lei 9.609/1998), a qual define em seu art. 11 que a figura do autor que pode ser pessoa física ou jurídica e indica os direitos exclusivos sobre a autoria do programa. Seguindo análise, a Lei específica, 9.609/1998, define em seu artigo $1^{\circ}$ o que significa "Programa de Computador"7 . Em que pese a definição adotada pela legislação seja ampla, o que aparece como algo positivo - trabalha com conceitos como "conjunto de instruções em linguagem natural ou codificada" e "contida em suporte físico de qualquer natureza" - o que abrangeria alguns dos exemplos mais avançados de IA, no momento, a referida legislação tem escopo exclusivo no se refere à propriedade intelectual. Seus tópicos tratam basicamente do registro e proteção de direitos autorais, penalidades para infração a estes direitos, algumas garantias aos usuários dos programas e sobre contratos de licença, uso, comercialização e transferência de tecnologia.

O Decreto 2.556/98 que trata da proteção e comercialização de Programas de Computador centra-se especificamente na questão do registro junto ao Instituto Nacional de Propriedade Industrial, vinculado ao Ministério da Economia. Outros instrumentos normativos são Resoluções e Instruções Normativas, todas dispondo sobre procedimentos de registro. Por fim, a Lei 13.709/2018 refere o tratamento de dados pessoais por pessoas naturais ou jurídicas de Direito Público e Privado, inclusive nos meios digitais, categorizando os "dados como dados pessoais", "dados pessoais sensíveis" e "dados anonimizados". A definição dos mesmos é dada pelo Art. 5”, I, II e III da norma. Seu principal objeto é a garantia de Direitos Fundamentais consagrados no Art. $5^{\circ}$ da Constituição Federal de 1988. Entretanto, quando menciona o rol de agentes que podem ser responsabilizados pelo vazamento de dados não menciona a situação hipotética deste evento ser causado por I. A., algo que é tão possível de ocorrer quanto o fato de que o sol despontará no céu, novamente, amanhã. Realizado o exame supra, verifica-se que a legislação brasileira sobre "programas de computador" em que se pode enquadrar a I. A., tendo em vista que nenhuma norma brasileira utiliza o termo "Inteligência Artificial" até o momento, não prevê absolutamente nada além do direito de propriedade do autor/desenvolvedor, seja pessoa física ou jurídica, bem como as formas de registro desta propriedade a fim de que produza seus efeitos jurídicos, inclusive com relação a terceiros que violem a propriedade intelectual.

Enquanto a IA está sendo amplamente utilizada no dia a dia, para a realização das mais diversas atividades, inclusive em outros níveis que implicam na capacidade de autoaprendizagem e aprendizagem profunda (machine learning e deep learning) o que significa dizer que a máquina pode aprender e realizar tarefas sem prévia programação específica para tal e, no segundo caso, agir a partir de redes neurais que simulam o funcionamento do cérebro humano, não há qualquer

\footnotetext{
7 “Art. $1^{\circ}$. Programa de computador é a expressão de um conjunto organizado de instruções em linguagem natural ou codificada, contida em suporte físico de qualquer natureza, de emprego necessário em máquinas automáticas de tratamento da informação, dispositivos, instrumentos ou equipamentos periféricos, baseados em técnica digital ou análoga, para fazê-los funcionar de modo e para fins determinados." (BRASIL, 1998b).
} 
legislação que dê suporte para as situações que podem emergir desta utilização. ${ }^{8}$ Outro viés relevante é o fato de que desenvolvedores de IA altamente sofisticadas, cujo investimento é de algumas centenas de bilhões de dólares, manterão os códigos-fontes destas tecnologias fechados, pois na maioria das vezes se tratam de segredos industriais do qual as empresas não têm interesse em revelar e popularizar, de modo que o Estado não tem qualquer controle sobre os algoritmos e a utilização desta tecnologia, concentrada e centrada nas mãos de grandes empresas transnacionais.

Qual é a responsabilidade das empresas, do Estado e da população diante de tão complexo cenário? Se forem resgatados os exemplos anteriores, das aplicações na contemporaneidade, quem se responsabiliza pelos ferimentos causados por IA, ou as mortes. Considere-se outros exemplos, como erro de uma IA médica (como um robô cirurgião) durante uma cirurgia, ou pela substituição nos postos de trabalho, ou pelos impactos na saúde física e psicológica gerados por IA $^{9}$, por violação de Direitos Fundamentais como o direito à privacidade, ao ambiente sadio e ecologicamente equilibrado (pensando em produção e descarte). Pensando em termos de responsabilidade civil, conta-se com o Art. 186 do Código Civil (Lei 10.406/2002), determina que "Aquele que, por ação ou omissão voluntária, negligência ou imprudência, violar direito e causar dano a outrem, ainda que exclusivamente moral, comete ato ilícito." (BRASIL, 2002). Lançando este olhar pelo prisma da responsabilidade civil, se está a considerar a reparação de um dano já consumado, mas seria mais adequado adotar uma legislação preventiva, já que não se sabe os riscos que a I. A. oferece às pessoas.

Veja-se o caso da IA no judiciário, como lidar com o "juiz-robô" por exemplo? No Brasil a adoção da tecnologia não implica em julgamento de casos, mas ao que parece este é o caminho a se consolidar no futuro, tal como proposto na Estônia, o que fazer em casos em que o julgamento resta equivocado, como o Direito receberá e organizará estes procedimentos? De todo modo a legislação é carecedora de elementos que possibilitem atender a este momento em que se vive. $\mathrm{O}$ próximo passo da pesquisa foi identificar fontes externas do Direito que pudessem servir de subsídio à formulação de um regulamento pátrio para o tema em questão ou matéria para a realização do diálogo de Fontes do Direito que será abordado no último tópico.

Ao realizar buscas no Direito Comparado sobre IA constatou-se que que há regulação de alguns temas em outros países. ${ }^{10}$ Em 16 de junho de 2017, a Alemanha realizou alterações no Código de Estradas, inserindo cinco artigos na referida lei para cumprir a finalidade de regular a utilização de veículos parcialmente ou totalmente autônomos. ${ }^{11}$ Observa-se, com isso, o esforço em detalhar as responsabilidades de cada envolvido/a com a utilização deste tipo de equipamento. Em agosto do mesmo ano a Comissão de Ética do Ministério Federal dos Transportes e Infraestruturas Digitais complementou as disposições da norma elaborada com a publicação do primeiro Código de Ética do mundo voltado para a programação deste tipo de veículo. No mencionado Código há vinte regras que determinam o compromisso ético de sobrelevar a

\footnotetext{
8 No sentido de corrigir esse vácuo legal, se encontra em construção o PL n ${ }^{\circ}$ 5051, de 2019, junto ao Senado Federal, de autoria do Senador Styvenson Valentin (PODEMOS/RN), no sentido de estabelecer os princípios para o uso da Inteligência Artificial no Brasil, o qual foi apresentado em 16/09/2019. O PL pode ser observado integralmente em https://www25.senado.leg.br/web/atividade/materias/-/materia/138790.

9 As tecnologias impactam profundamente sobre aspectos físicos e psíquicos, a exemplo disso há diversos centros de pesquisa e tratamento da dependência do uso de internet, tanto no Brasil quanto no exterior, dos quais cita-se o Ambulatório Integrado do Controle dos Impulsos, do Instituto de Psiquiatria do Hospital das Clínicas da USP, em São Paulo, considerado como referência no assunto.

${ }_{10}$ Com base em relatório produzido por Autocits e Diálogos União Europeia-Brasil sobre Inteligência Artificial e Regulação de Algoritmos (referência ao final do texto) foi identificada a existência ou ausência de regulação em cinco categorias: veículos autônomos, veículos não tripulados, robôs, negócios na internet e resolução de conflitos.

11 “[...] definindo veículos parcialmente ou totalmente autónomos; permitindo a utilização destes veículos desde que esteja sempre presente um condutor que possa, a qualquer momento retomar o controlo (sic) do veículo; introduzindo a obrigação de os veículos serem equipados com uma caixa negra (sic) que seja capaz de registar os dados mais relevantes para, em caso de acidente, se determinar sobre quem deve cair a responsabilidade: o condutor ou o produtor." (NOVAIS; FREITAS, 2018, p. 47).
} 
segurança das pessoas em qualquer hipótese determinando inclusive que os equipamentos sejam dotados de dispositivos de troca de controle de forma abrupta se, necessário, a fim de que se diferencie mais claramente falha humana de falha da IA.

No mesmo sentido, já há regulação no que tange aos automóveis autônomos na Espanha, França $^{12}$ (em Paris), Portugal (com restrições ao tráfego), Suécia, Holanda e Dinamarca. Na Itália é possível sua utilização, mas não em rodovias. Outros Estados não europeus também contam com alguma legislação como Singapura, Coreia do Sul, China, Japão e Austrália há permissão, sendo estipulada a permissão para uso da tecnologia, mas sem um detalhamento maior (AUTOCITS, 2017(?)). Na maioria dos países citados o foco é a permissão ou não para o tráfego em diferentes níveis, em especial para a finalidade de testagem dos equipamentos, sendo a Alemanha a pioneira em regular efetivamente o assunto. ${ }^{13}$ As normas citadas determinam especificações sobre tamanho e peso dos drones, a necessidade de autorização prévia para o uso, distâncias mínimas de utilização com relação a pessoas e hospitais, circunstâncias em que podem ser usados e área geográfica de tráfego. Também Portugal legislou no mesmo sentido, porém avançando no que se refere à definição de "operações autônomas" com drones, bem como sobre operações à linha de vista ou

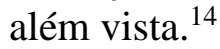

No que tange à proteção de dados pessoais, há regulamento específico abrangendo toda a União Europeia, qual seja o Regulamento (UE) 2016/679 do Parlamento Europeu e do Conselho, de 27 de abril de 2016, relativo à proteção das pessoas singulares no que diz respeito ao tratamento de dados pessoais e à livre circulação desses dados. Tal regulamento é obrigatório para todos os Estados-Membros. Sobre mercados financeiros e negociação algorítmica foram encontradas as seguintes normas: Diretiva 2014/65/UE do Parlamento Europeu e do Conselho de 15 de maio de 2014 relativa aos mercados de instrumentos financeiros e que altera a Diretiva 2002/92/CE e a Diretiva 2011/61/EU; Regulamento (UE) n. ${ }^{\circ}$ 596/2014 do Parlamento Europeu e do Conselho, de 16 de abril de 2014, relativo ao abuso de mercado (regulamento abuso de mercado) e que revoga a Diretiva 2003/6/CE do Parlamento Europeu e do Conselho e as Diretivas 2003/124/CE, 2003/125/CE e 2004/72/CE da Comissão. (NOVAIS; FREITAS, 2018).

$\mathrm{Na}$ Alemanha, em 2013, entrou em vigor a Gesetz zur Vermeidung von Gefahren und Missbräuchen im Hochfrequenzhandel (Hochfrequenzhandelsgesetz), a qual modificou as leis do sistema bancário e de investimentos ${ }^{15}$. Em Portugal a legislação sobre o assunto é o Decreto-Lei número 486/99. (NOVAIS; FREITAS, 2018). Sobre a utilização de robôs autônomos há

12 Interessantemente a legislação francesa proibiu a utilização de I. A. pelos juízes.

13 Com relação ao uso de drones (veículos não tripulados), o tema foi regulado pelo Direito alemão sendo que "O marco legal de referência no ordenamento jurídico alemão é o Verordnung zur Regelung des Betriebs von unbemannten Fluggerätem, de 30 de março de 2017. Este diploma introduziu uma série de modificações legais, sendo as mais significativas as verificadas na Luftverkehrs-Ordnung (LuftVO) - a regulamentação do tráfego aéreo. Neste último diploma, mais concretamente na seção 5a, dos artigos 21a a 21f." (NOVAIS; FREITAS, 2018, p. 56).

14 "A operação à linha de vista (Visual Line-of-Sight) consiste "na operação segundo as regras de voo visual em que o piloto remoto ou o observador da aeronave pilotada remotamente mantém contacto visual direto, sem ajuda, com a referida aeronave" (artigo 2, al. v), enquanto a operação além da linha de vista (BVLOS, Beyond Visual Line-of-Sight) acontece quando estamos perante uma "operação segundo as regras de voo visual em que o piloto remoto ou o observador da aeronave pilotada remotamente mantém contacto visual direto, sem ajuda, com a referida aeronave" (artigo 2, al. w). Podemos dizer que genericamente podem ser operados drones em operações VLOS até uma altitude de 120 metros, desde que sejam minimizados os riscos e perigos para outras aeronaves, pessoas ou bens (artigo 3 ), ao passo que as operações BVLOS carecem em regra de autorização expressa da Autoridade Nacional da Aviação Civil, a não ser que a massa operacional seja igual ou inferior a 1 quilograma, não seja excedida uma altura de 5 metros, o equipamento esteja munido de modo de operação first-person-view, o voo se realize num raio de 100 metros tendo por referência o piloto, o voo seja em local afastado de pessoas e bens e o risco de colisão com pessoas e bens de terceiros seja inexistente." (NOVAIS; FREITAS, 2018, p. 59).

15 O texto original da Gesetz zur Vermeidung von Gefahren und Missbräuchen im Hochfrequenzhandel

(Hochfrequenzhandelsgesetz) pode ser apreciado em

https://bvai.de/fileadmin/PDFs/DE/Reg._Rahmenbedingungen_Stellungnahmen/Hochfrequenzhandelsgesetz/HFT-

Gesetz-final.pdf.

Revista de Direito Brasileira | Florianópolis, SC | v. 28 | n. 11 | p.405-421 | Jan./Abr. 2021 
recomendação do Parlamento Europeu no sentido de realizar disposições de Direito Civil sobre robótica, no entanto, os Estados ainda não legislaram especificamente sobre o tema, havendo indicação de vários parlamentos dos Estados-Membros neste sentido. A resolução P8_TA(2017)0051 data de 16 de fevereiro de 2017 e pode ser consultada na íntegra na página eletrônica do próprio Parlamento. ${ }^{16}$ A referida recomendação traz um extenso conjunto de diretrizes para a elaboração de regulamentos sobre este tópico incluído as seguintes questões: princípios gerais; responsabilidade; princípios gerais relativos ao desenvolvimento da robótica e da inteligência artificial para utilização civil; Investigação e Inovação; princípios éticos; criação de uma agência europeia; direitos de propriedade intelectual e circulação de dados; meios de transporte autônomos (veículos e drones); robôs de assistência; robôs médicos; reparação e aperfeiçoamento humano; responsabilidade; aspectos internacionais e aspectos finais necessários para a regulação. ${ }^{17}$

\section{DIAGNÓSTICO E PROGNÓSTICO EM TERMOS DE REGULAÇÃO}

Diante das informações apuradas se constata que o Brasil está muito aquém no que se refere a legislar sobre a IA, porém outros, quiçá a maioria dos países, também já convivem com a utilização desta tecnologia sem que haja efetiva regulação. Os Estados mais avançados neste sentido, ao que se pode identificar, são a Alemanha e Portugal. A União Europeia surge como entidade promotora e propulsora da regulação considerando a recomendação do Parlamento europeu neste sentido.

De outra banda, transnacionais como Microsoft, Amazon, Facebook, IBM, Intel, Sony, Google e Apple estão reivindicando regulação por parte dos Estados e participam de iniciativas como a Partnership on A. I., uma parceria global formada por pesquisadores/as, acadêmicos/as, empresas, organizações da sociedade civil para pesquisa, aperfeiçoamento e busca de boas práticas de utilização da I. A. ${ }^{18}$ São mais de 80 parcerias, em treze países, mais de $50 \%$ são entidades sem fins lucrativos. ${ }^{19}$ Não se pode desconsiderar também publicações das próprias empresas como "The Future Computed" ${ }^{20}$ lançada pela Microsoft em 2018, a qual trata, dentre outros temas, da urgência em estabelecer marcos legais para apuração de responsabilidades, direitos e deveres de fabricantes e usuários, limites éticos e solução de controvérsias.

Avaliando a parca legislação, mas a existência de materiais, recomendações, pesquisas, discussões e parcerias no sentido de refletir sobre o impacto da IA na sociedade, economia, saúde, mercado de trabalho, o prognóstico a ser pensado perpassa pelo imperativo de uma releitura do Direito e sua abertura para buscar novas alternativas à obsolescência das normas existentes, a demanda de novas legislações e a superação do demorado processo legislativo dos Estados. Ao se debruçar sobre pontos forte ou fracos da legislação, verifica-se que considerando a ausência de legislação sobre o tema no Direito brasileiro, resta prejudicada esta análise, o que se pode apontar é para a busca de caminhos alternativos para a carência já apontada. Sobre esses caminhos - ou como colocado anteriormente - sobre este prognóstico que se discute a seguir.

16 Documento na íntegra disponível em http://www.europarl.europa.eu/doceo/document/TA-8-20170051_PT.html?redirect\#BKMD-13

17 Esmiuçando os tópicos a recomendação refere a necessidade de normas para regulação e registro dos robôs, o estabelecimento do princípio da precaução, responsabilidade, proteção de Direitos Fundamentais, proteção ao Ambiente, dentre outras questões.

18 A Partnership on A.I explica em sua página que "A parceria para beneficiar pessoas e sociedade foi criada para estudar e formular as melhores práticasem tecnologias de I. A., para promover o entendimento do público sobre I. A. e para servir como plataforma aberta para discussão e engajamento sobre I. A. e suas influências nas pessoas e na sociedade."

19 Disponível em https://www.partnershiponai.org/

20 Obra disponível em e-book em https://news.microsoft.com/uploads/2018/01/The-Future-Computed.pdf. Revista de Direito Brasileira | Florianópolis, SC | v. 28 | n. 11 | p.405-421 | Jan./Abr. 2021 


\section{O DIÁLOGO DE FONTES COMO ALTERNATIVA ÀS FAGILIDADES DO DIREITO EM FACE DA IA}

As transformações vividas a partir da segunda metade do século XX possuem algumas características peculiares, de acordo com o sociólogo Ulrich Beck (2010) houve uma transição da antiga Sociedade Industrial para o que ele denomina como Sociedade de Risco, onde os riscos causados pela modernização, o domínio da técnica e da ciência produzem efeitos que atingem sujeitos indeterminados, ultrapassando a noção de classe social ou fronteiras político-geográficas. Dentro da compreensão de risco se pode enquadrar também a questão da IA, quando se arrazoa sobre temas como impactos de produção e uso das mesmas, pois como já comentado anteriormente, esta tecnologia acarreta muitos reflexos em diversos âmbitos da vida humana que visivelmente transcendem as duas noções sublinhadas acima, e que evidentemente, em parte, são ainda desconhecidos.

A produção de riscos advinda da manipulação da técnica/ciência, aliada ao fenômeno da globalização, oportunizou que se amplificasse de forma exponencial a velocidade dos avanços tecnocientíficos, sem que com isso, pudesse o Direito acompanhar essas trajetórias, pois o Direito Positivo possui a característica de progredir sempre a reboque dos acontecimentos. Portanto:

[...] así es precisamente como fracasan las instituciones. Puesto que fueron diseñadas desde una óptica nacional, no están preparadas para la realidad cosmopolita. Esto es aplicable, por cierto, a todos los riesgos globales: las respuestas basadas em la perspectiva nacional y los instrumentos políticos y legales que nos oferecen nuestras instituciones ya no están a la altura del desafio que representa hoy la sociedad del riesgo global. (BECK, 2017, p. 148).

Este é o contraponto essencial, pois se está diante da problemática do vácuo legislativo com relação a IA, carência que não é exclusividade do Direito brasileiro como se pode apurar no decorrer do trabalho. Contudo, tomando como recorte obrigatório o Direito pátrio (como arrancada para uma visão mais cosmopolita), ao se analisar o Direito Privado como ponto de partida para a regulação da IA é inevitável realizar a releitura da Teoria do Fato Jurídico de Francisco Cavalcanti Pontes de Miranda e considerar o diálogo de Fontes do Direito como condição de possibilidade para auxiliar no equacionamento da lacuna normativa.

Tanto Pontes de Miranda quanto Hans Kelsen se assemelham na forma de conceber o sistema jurídico, pois consideram o mesmo como um sistema lógico, dotado de premissas em que o fato da vida vai encaixando-se ao suporte fático previsto na norma previamente estabelecida, para finalmente produzir os efeitos jurídicos nela contidos. Este caminho obrigatório de conexão entre o fato e o suporte estabelece a logicidade do sistema. (ENGELMANN, 2010). Ainda nesta linha de raciocínio, a Teoria do Suporte fático se desdobra em três planos - plano da existência, plano da validade e plano da eficácia - de modo que o fato para adentrar no mundo jurídico precisa subsumir a estas três premissas - tendo como centro da técnica legislativa a pessoa ou a ofensa à pessoa, ou seja, o elemento subjetivo "ser humano" dentro desta lógica é obrigatoriamente parte do suporte fático, pois:

Os fatos juridicizáveis, estão, sempre, ligados a uma pessoa, ou porque digam respeito a ela (nascimento, maioridade, morte, casamento), ou porque atinjam a sua esfera jurídica, ou se refiram ao seu modo de atuar. O direito obtém a adaptação social, que faz o processo social específico, através de relações entre pessoas. (PONTES DE MIRANDA, 1954, tomo I, p. 24).

Dito isso, para uma regulação sobre IA, em face do caso concreto, há alguns pontos a discutir pois: a) não é possível prever todas as situações que podem envolver desenvolvimento e 
uso desta tecnologia ${ }^{21}$; b) ainda não há como avaliar todos os direitos e deveres que podem emergir com relação a ela; c) não é possível identificar os riscos que oferece; d) não é possível aferir os impactos que produzirá sobre a vida das pessoas e ambiente; e) a tecnologia é produzida e utilizada em espaço transnacional.

Percebe-se com isso a dificuldade de aplicar a clássica Teoria do Suporte Fático com relação à $\mathrm{IA}$, pois a tecnologia não converge com a previsibilidade da lógica jurídica e nem tão pouco com a utilização de uma estrutura legal hierárquica que tenha em conta apenas o Direito legislado pelo Estado Nacional ${ }^{22}$. Corroborando, destaque-se que, com o advento da Constituição Federal de 1988 se desencadeou o fenômeno da constitucionalização do Direito Privado, de modo que suas disposições devem passar obrigatoriamente pelo filtro constitucional para o propósito de atender aos Direitos Fundamentais propostos pela norma fundamental do Estado brasileiro.

Partilha-se da concepção de Engelmann (2010, p. 296) quando indica que "o grande desafio é gerar uma teoria que possa identificar os elementos do suporte fático no Direito e não na lei". Com esta afirmação aponta para um novo horizonte que envolve o diálogo de fontes do Direito discorrendo que:

Uma das características da pluralidade de fontes é considerar além da lei no seu sentido mais lato, com ênfase na Constituição da República, os princípios e a jurisprudência - notadamente aquela expressa em Súmulas e, mais recentemente, também as Súmulas Vinculantes, as decisões judiciais projetadas nos acórdãos dos Tribunais - a doutrina, os costumes, os contratos, o poder normativo dos grupos sociais, as decisões oriundas da negociação, mediação e arbitragem, as normas internacionais, como o "direito de produção" e a Lex mercatória, os Tratados e Convenções Internacionais, costumes internacionais e os princípios gerais do Direito Internacional. Esse conjunto é que se deverá considerar como a expressão "Fontes do Direito" e é nele que se deverá potencializar o diálogo. Uma teoria do Fato Jurídico deverá dar conta da juridicidade por este conjunto plural e coordenado de fontes. (ENGELMANN, 2010, p. 295-296).

Resta desta maneira caracterizada a noção de Fontes do Direito, bem como o diálogo entre elas. Como (re)leitura da Teoria do Fato Jurídico, no caso, o jurista indica que se estabeleça da seguinte forma: o plano da existência seria relido como plano da interação ${ }^{23}$; o plano da validade como plano da instituição ${ }^{24}$; e o plano da eficácia como plano da sociedade ${ }^{25}$. A proposta de Diálogo de Fontes pode ser encontrada também nas teorizações de Gunther Teubner, ao tratar do

\footnotetext{
21 A teoria pontesiana, sem dúvidas, guarda consigo imensa relevância, contudo, diz respeito a um momento histórico que se mostra já superado. Diante da I.A. capaz de aprendizagem, autoaprendizagem, pensamento e reflexão, a premissa de que o fato da regra jurídica "[...] existe no mundo das relações humanas e do pensamento humano; [...]" (PONTES DE MIRANDA, 1954, p. 3) já não atende mais aos fenômenos que se desenvolvem atualmente.

22 Percebe-se a emergência de um panorama dualista: na busca de certeza e previsibilidade de decisões e dados por meio da IA, encontra-se uma nova forma de incerteza e imprevisibilidade, agora gerada pelo sistema de IA. Até agora, as principais características do sistema jurídico romano-germânico, especialmente, era a previsão dos comportamentos em textos legislativamente produzidos, onde segurança e previsibilidade são elementos estruturantes fundamentais. Quando se volta para um cenário mais flexível e permeável, ingressa-se em um contexto onde a certeza e previsibilidade não estão mais nos textos legais, mas nas diversas etapas do sistema de IA. (ENGELMANN; WERNER, 2019, p. 174).

23 No lugar de apenas verificar se foram preenchidos os elementos previstos pelo suporte fático, se passa a realizar a interação do fato da vida com as diversas normas a fim de identificar uma solução constitucionalmente viável. (ENGELMANN, 2010).

24 Ao invés de identificar apenas se o fato é válido, nulo ou anulável, se busca a utilização de princípios que comportem os Direitos Naturais-Humanos essenciais à produção de efeitos jurídicos. (ENGELMANN, 2010).

25 Enquanto no plano da eficácia se concretiza a produção de efeitos jurídicos, no plano da sociedade se concretiza a função político social. (ENGELMANN, 2010).
}

Revista de Direito Brasileira | Florianópolis, SC | v. 28 | n. 11 | p.405-421 | Jan./Abr. 2021 
tema "Fragmentos Constitucionais e Constitucionalismo social na globalização"26, onde indica não só a insuficiência das Constituições dos Estados Nacionais em dar respostas aos pleitos transnacionais que se colocam neste momento histórico, bem como trata da dificuldade de estabelecer uma Constituição Global, apostando na colisão e conexão em rede das Constituições Transnacionais e na eficácia de Direitos Fundamentais Transnacionais.

Teubner discorre acerca de uma compreensão ampliada do conceito de Constituição, categorizando quais seriam os sujeitos constitucionais transnacionais, bem como o que são as normas constitucionais transnacionais (por isso "fragmentos constitucionais" ${ }^{27}$, pois estão fora do âmbito de normas produzidas por parlamentos de Estados Soberanos, constituindo formas sui generis de regulação) (TEUBNER, 2016). Tal prisma privilegia, portanto, uma compreensão sistêmica, de leitura horizontal das fontes do Direito, abandonando com isso o antigo modelo hierarquizado de organização das normas.

Neste caminho também circulam as teorizações de Mireille Delmas-Marty quando destaca que o modelo piramidal de Kelsen "dificilmente dá conta da paisagem observada" (DELMASMARTY, 2004, p. 86), nas palavras da própria jurista. Sua análise demonstra que este modelo não se sustenta nem no aspecto temporal e nem diante da heterogeneidade espacial. Cita como exemplo o Direito supranacional que não está submetido de forma vertical. Assim:

Resta a dificuldade, praticamente insuperável, de colocar nessa - ou nessas hierarquia(as) normativa(s) os princípios gerais do direito que foram descritos a um só tempo fora do sistema como o direito natural e integrados a ele, pois de direito positivo; de direito interno e de direito internacional; escritos e não escritos; superiores e iguais às leis. E, finalmente, ao mesmo tempo iguais e desiguais entre si. Em tal turbilhão, a imagem da pirâmide é substituída por estranhos anéis que evocam "raminhos de uma guirlanda eterna" pelos quais, reunindo matemática (a teoria de Gödel), pintura (as gravuras de Escher) e música (as fugas de Bach),o matemático Hofstadter mostra como a consciência faz pouco caso das hierarquias. Aos enredamentos por ele descritos - aqueles que "surgem quando uns sistemas se voltam para si próprios, por exemplo, quando a ciência estuda a ciência, quando o governo se debruça sobre as infrações do governo, quando a arte viola as regras da arte e, para terminar, quando os humanos refletem sobre seus próprios cérebros e mentes" -, seria tentador acrescentar aqueles que surgem com as fontes múltiplas do direito, quando o direito questiona os direitos. Em resumo, poderíamos dizer que, se o plano de composição se embaralhou, não é porque tenha desaparecido toda a hierarquia, mas porque mudou o desenho. Em vez da hierarquia contínua e linear que a imagem da pirâmide expressava, aparecem hierarquias descontínuas, como tantas outras pirâmides inacabadas, e hierarquias enredadas que formam anéis estranhos", retomando a imagem de Hofstadter. (DELMAS-MARTY, 2004, p. 87).

A imagem de um conjunto de anéis flexíveis e sobrepostos ${ }^{28}$ em um emaranhado de Fontes de Direito ensejam uma harmonização de sistemas jurídicos distintos, sem que com isso se opere unificação dos mesmos, o que poderia gerar novamente a composição verticalizada.

26 Título de obra de sua autoria, publicada em 2016.

27 Organização das Nações Unidas, Organização Mundial do Comércio, Corporation for Assigned Names and Numbers - ICANN, Organizações Internacional de Normalização - ISO e trazendo como fragmentos constitucionais a Lex Mercatória, Lex Esportiva, o soft law presente no Direito Nacional e Internacional, os regulamentos internos das empresas transnacionais, dentre outros.

28 “"...] essa sobreposição permite todo um jogo de referências cruzadas (de um país ou de uma região à outra, mas também de um nível nacional, regional ou mundial ao outro), o que facilita a elaboração de princípios comuns, não só declarativos, mas que regem as escolhas e a interpretação das normas jurídicas nacionais." (DELMAS-MARTY, 2004, p. 289).

Revista de Direito Brasileira | Florianópolis, SC | v. 28 | n. 11 | p.405-421 | Jan./Abr. 2021 
Resumidamente surge "[...] a possibilidade de conceber um espaço normativo feito de vários conjuntos, uns perfeitamente ordenados, outros parcialmente, outros ainda não ordenados." (DELMAS-MARTY, 2004, p. 288).

No âmbito da I. A. o espaço normativo seria composto pelos diversos conjuntos conforme mencionado acima, quais sejam estes: os fragmentos normativos brasileiros aplicáveis (legislação interna já estudada), as orientações do Parlamento Europeu sobre o tema, as normas portuguesas e alemãs e os documentos emergentes do esforço conjunto operado pela Partnership on A. I., bem como outras fontes que não foram especificamente nominadas, de outros Estados ou que ainda serão desenvolvidas, sendo parte disso a passagem destes grupos pelo filtro constitucional proporcionado pela Constituição Federal de 1988.

Ao se examinar as proposições de Engelmann (2010), Teubner (2016) e Delmas-Marty (2004) nota-se um fio condutor que encaminha para uma nova percepção do Direito apoiada na horizontalidade, em redes, anéis flexíveis e conexões de diversas fontes normativas, num emaranhado de caminhos possíveis. Estas são as características de um sistema jurídico que se possa denominar como "justecnológico", alinhado com as demandas de seu tempo e vislumbrando o futuro.

\section{CONSIDERAÇÕES FINAIS}

O estudo envolveu teve como tema a Inteligência Artificial e o seu objetivo foi identificar se o diálogo entre fontes do Direito pode ser adotado a fim de contemplar novos direitos que emergem da interação com esta tecnologia. Foram analisadas algumas das suas mais recentes utilizações. Buscou-se a legislação sobre IA no Direito brasileiro e comparado, o que resultou na constatação de vácuo legislativo nas duas esferas, mas a existência de outros documentos passíveis de utilização como a recomendação do parlamento europeu sobre IA e iniciativas público-privadas como a Partnership on A.I. Compreende-se o diálogo de fontes como alternativa às fagilidades do direito em face da I A, se discutiu as teorizações de Engelmann, Teubner e Delmas-Marty, em face da carência normativa sobre o tema, inclusive considerando $o$ fato de que $o$ desenvolvimento/produção e uso da tecnologia em escala transnacional, envolvendo sujeitos transnacionais.

O cenário apresentado pelo desenvolvimento e a utilização contemporânea da IA está para além da organização clássica do Direito, sendo este insuficiente para atender as celeumas que emergem dos avanços tecnológicos atuais, pois estes fenômenos estão à margem da abrangência de teorizações como a do suporte fático pontesianas ou da hierarquia das normas kelsenianas, lançando a IA em uma zona de penumbra normativa. No entanto, a aproximação das proposições de Engelmann (2010), Teubner (2016) e Delmas-Marty (2004) perfectibilizou a hipótese aventada no início do estudo, pois que é viável o delineamento de um fio condutor que encaminha para novas percepções do Direito, com características de um sistema jurídico que se possa denominar como "justecnológico", composto pelo diálogo de fontes alinhado com as demandas de seu tempo e vislumbrando o futuro, contemplando os direitos que emergem da interação entre humanos e Inteligência Artificial.

Considerando essa via de acesso a regulação da IA pode se desenvolver nesta horizontalidade, conectiva, em rede, emaranhada e veloz, compondo-se com a legislação interna, orientações do Parlamento Europeu, normas portuguesas e alemãs, documentos emergentes do esforço conjunto operado pela Partnership on A. I., bem como outras fontes já existentes ou vindouras, sendo parte deste processo a passagem destes grupos pelo filtro proporcionado pela Constituição Federal de 1988. 


\section{REFERÊNCIAS}

AUTOCITS CONSORTIUM. Regulation Study for Interoperability in the Adoption of Autonomous Driving in European Urban Nodes. INDRA. UE. (2017?). Disponível em https://www.autocits.eu/sites/autocits/files/AUTOCITS\%20Regulation\%20study_ABSTRACT.p df. Acesso em 13 de julho de 2019.

BECK, Ulrich. Sociedade de Risco: rumo a uma outra modernidade. (Trad.: Sebastião Nascimento). São Paulo: Ed. 34, 2010.

BECK, Ulrich. La Metamorfosis Del Mundo. (Trad.: Fernando Borrajo Castanedo). Barcelona: Paidós, 2017.

BRASIL. Lei n ${ }^{\circ}$ 9.279, de 14 de maio de 1996. Regula direitos e obrigações relativos à propriedade industrial. Disponível em http://www.planalto.gov.br/ccivil_03/leis/19279.htm. Acesso em 12 de julho de 2019.

BRASIL. Lei n ${ }^{\circ}$ 9.609, de 19 de fevereiro de 1998a. Dispõe sobre a proteção da propriedade intelectual de programa de computador, sua comercialização no País, e dá outras providências. Disponível em http://www.planalto.gov.br/ccivil_03/leis/L9609.htm. Acesso em 12 de julho de 2019.

BRASIL. Lei n ${ }^{\circ}$ 9.610, de 19 de fevereiro de 1998b. Altera, atualiza e consolida a legislação sobre direitos autorais e dá outras providências. Disponível em http://www.planalto.gov.br/ccivil_03/leis/19610.htm. Acesso em 12 de julho de 2019.

BRASIL. Decreto ${ }^{\circ} 2.556$, de 20 de abril de 1998. Regulamenta o registro previsto no art. $3^{\circ}$ da Lei $\mathrm{n}^{\circ}$ 9.609, de 19 de fevereiro de 1998, que dispõe sobre a proteção da propriedade intelectual de programa de computador, sua comercialização no País, e dá outras providências. Disponível em http://www.planalto.gov.br/ccivil_03/decreto/D2556.htm. Acesso em 12 de julho de 2019.

BRASIL. Lei ${ }^{\circ} 10.406$, de 10 de janeiro de 2002. Institui o Código Civil. Disponível em http://www.planalto.gov.br/ccivil_03/leis/2002/L10406compilada.htm. Acesso em 12 de julho de 2019.

BRASIL. Lei n ${ }^{\circ}$ 13.709, de 14 de agosto de 2018. Lei Geral de Proteção de Dados Pessoais. Disponível em http://www.planalto.gov.br/ccivil_03/_ato2015-2018/2018/lei/L13709.htm. Acesso em 13 de julho de 2019.

BRASIL. SUPREMO TRIBUNAL FEDERAL. Ministra Cármen Lúcia anuncia início de funcionamento do Projeto Victor, de inteligência artificial. Notícias STF. 30/08/2019. Disponível em http://www.stf.jus.br/portal/cms/verNoticiaDetalhe.asp?idConteudo=388443. Acesso em 09 de julho de 2019.

COELHO, Carlos. Robô usado na segurança de shopping fere criança de um ano e quatro meses. Gazeta do Povo. Tecnologia. 13/07/2016. Disponível em https://www.gazetadopovo.com.br/economia/inteligencia-artificial/robo-usado-na-seguranca-de- 
shopping-fere-crianca-de-um-ano-e-quatro-meses-9gp4xflk9qey1ods5ntckbfqt/. Acesso em 09 de julho de 2019.

DELMAS-MARTY, Mireille. Por um direito comum. Tradução de Maria Ermantina de Almeida Prado Galvão. São Paulo: Martins Fontes, 2004.

ENGELMANN, Wilson. Direitos Bio-Humano-Éticos: os humanos buscando "direitos" para proteger-se dos avanços e riscos (desconhecidos) das nanotecnologias. In: XIX Encontro Nacional do CONPEDI, 2010, Fortaleza. Anais do XIX Encontro Nacional do CONPEDI. Florianópolis: Editora da Fundação Boiteux, 2010. v. 1.

ENGELMANN, Wilson. A (re)leitura da teoria do fato jurídico à luz do "diálogo entre as fontes do direito": abrindo espaços no direito privado constitucionalizado para o ingresso de novos direitos provenientes das nanotecnologias. IN: STRECK, Lenio Luiz e MORAIS, José Luis Bolzan de. (Orgs.). Constituição, Sistemas Sociais e Hermenêutica: Anuário do Programa de PósGraduação em Direito da Unisinos: Mestrado e Doutorado. Porto Alegre: Livraria do Advogado, 2011, n. 7. pp. 289-308.

ENGELMANN, Wilson; WERNER, Deivid Augusto. Inteligência Artificial e Direito. In: FRAZÃO, Ana; MULHOLLAND, Caitlin. (Coords.). Inteligência Artificial e Direito: Ética, Regulação e Responsabilidade. São Paulo: Thomson Reuters Brasil, Revista dos Tribunais, 2019. pp. 149-178

GALILEU. Robô Sophia embarca em turnê mundial para promover inteligência artificial. Editora Globo. Portal de Notícias G1. 2018. Disponível em https://revistagalileu.globo.com/Tecnologia/noticia/2018/10/robo-sophia-embarca-em-turnemundial-para-promover-inteligencia-artificial.html. Acesso em 09 de julho de 2019.

INSTITUTO HUMANITAS UNISINOS. Estes são os dez principais avanços tecnológicos de 2019 para Bill Gates. Revista IHU On-Line. Disponível em http://www.ihu.unisinos.br/78noticias/587208-estes-sao-os-dez-principais-avancos-tecnologicos-de-2019-para-bill-gates. Acesso em 03 de julho de 2019.

INTELIGÊNCIA artificial. Direção de Steven Spielberg. Produção de Steven Spielberg, Jan Harlan, Kathleen Kennedy, Walter F. Parkes, Bonnie Curtis. EUA: Amblin Entertainment Stanley Kubrick Productions, Warner Bros. Entertainment, DreamWorks Pictures, 2001. 1DVD (146 min).

LOBO, Luiz Carlos. Inteligência artificial, o Futuro da Medicina e a Educação Médica. Rev. bras. educ. med., Brasília, v. 42, n. 3, p. 3-8, Set. 2018. Disponível em http://www.scielo.br/scielo.php?script=sci_arttext\&pid=S0100$\underline{55022018000300003 \& \operatorname{lng}=e n \& n r m=i s o}$. Acesso em 05 de julho de 2019.

NOVAIS, Paulo; FREITAS, Pedro Miguel. Inteligência Artificial e Regulação de Algoritmos. Relatório. 30/05/2018. Ministério da Ciência, Tecnologia, Inovações e Comunicações, Brasil. União Europeia, Brasil. Disponível em 
https://www.mctic.gov.br/mctic/opencms/inovacao/paginas/politicasDigitais/assuntosCibernetico s/inteligencia-artificial-e-regulacao-de-algoritmos.html. Acesso em 13 de julho de 2019.

PONTES DE MIRANDA, Francisco Cavalcante. Tratado de Direito Privado. Parte Geral. Rio de Janeiro: Borsoi, 1954, tomo I (Introdução. Pessoas físicas e jurídicas), p. 1-35.

PORTAL DE NOTÍCIAS G1. A assustadora criança-robô que sangra, grita e simula dor: lançado nos estados unidos, o "simulador de pacientes pediátricos mais avançado do mundo" causa inquietação em muita gente. BBC News. 26/09/2018. Disponível em https://g1.globo.com/ciencia-e-saude/noticia/2018/09/26/a-assustadora-crianca-robo-que-sangragrita-e-simula-dor.ghtml. Acesso em 09 de julho de 2019.

PORTAL DE NOTÍCIAS G1. Robô agarra e mata trabalhador dentro de fábrica da Volkswagen. Mundo. G1, São Paulo. 01/07/2015. Disponível em http://g1.globo.com/mundo/noticia/2015/07/robo-agarra-e-mata-trabalhador-dentro-de-fabricada-volkswagen.html. Acesso em 09 de julho de 2019.

PORTAL DE NOTÍCIAS VOIT. Exterminador fofinho: robô ataca e fere uma pessoa na China. Notícias. 23/11/2016. Disponível em http://www.voit.com.br/exterminador-fofinho-robo-ataca-efere-uma-pessoa-na-china/. Acesso em 09 de julho de 2019.

REVISTA ÉPOCA. 10 avanços da tecnologia para ficar de olho em 2018, segundo o MIT. Revista Época, Época Negócios Online, mar. 2018. Disponível em https://epocanegocios.globo.com/Tecnologia/noticia/2018/03/10-avancos-da-tecnologia-paraficar-de-olho-em-2018-segundo-o-mit.html. Acesso em 03 de julho de 2019.

SARMATZ, Leandro; FONTENELLE, André. Os Truques de um Turco. Revista Super Interessante. 30/11/2002. Editora Abril. Disponível em https://super.abril.com.br/historia/ostruques-de-um-turco/. Acesso em 09 de julho de 2019.

SILVA, Rafael Rodrigues da. Estônia está desenvolvendo o primeiro juiz robô do mundo. Canaltech. Portal de Notícias MSN. 04/04/2019. Microsoft News. Disponível em https://www.msn.com/pt-br/noticias/ciencia-e-tecnologia/estônia-está-desenvolvendo-o-primeirojuiz-robô-do-mundo/ar-BBVBS2V. Acesso em 09 de julho de 2019.

SUPREMO TRIBUNAL FEDERAL. Ministra Cármen Lúcia anuncia início de funcionamento do Projeto Victor, de inteligência artificial. Notícias do STF. 30/08/2018. Disponível em http://www.stf.jus.br/portal/cms/verNoticiaDetalhe.asp?idConteudo=388443. Acesso em 09 de julho de 2019.

TEIXEIRA, João de Fernandes; QUILICI GONZALES, Maria Eunice. Inteligência Artificial e Teoria de Resolução de Problemas. Trans/Form/Ação, São Paulo 6: 45-52, 1983. Disponível em http://www.scielo.br/pdf/trans/v6/v6a06.pdf. Acesso em 05 de julho de 2019.

TEUBNER, Gunther. Fragmentos Constitucionais: constitucionalismo social na globalização. Coord. Marcelo Neves [et. al.]. São Paulo: Saraiva, 2016. 
TD. TRANSFORMAÇÃO DIGITAL. 4 aplicações da Inteligência Artificial em nosso dia a dia. Equipe TD. 20/12/2017. Disponível em https://transformacaodigital.com/4-aplicacoes-dainteligencia-artificial-em-nosso-dia-dia/. Acesso em 05 de julho de 2019.

UOL NOTÍCIAS; PORTAL DE NOTÍCIAS DA AGÊNCIA REUTERS. Você está demitido! Amazon abandona robô recrutador que virou machista. Por Jeffrey Dastin, traduzido pelo portal UOL. Disponível em https://noticias.uol.com.br/tecnologia/noticias/reuters/2018/10/11/voceesta-demitido-amazon-abandona-robo-recrutador-que-virou-machista.htm. Acesso em 08 de julho de 2019. 